Fanum

Sociológico

\section{Forum Sociológico}

Série II

22 | 2012

Saúde e multiculturalidade

\title{
O destino como projeto? Racionalidades leigas de promoção da saúde
}

\section{Luísa Ferreira da Silva}

\section{Q OpenEdition}

1 Journals

Edição electrónica

URL: https://journals.openedition.org/sociologico/696

DOI: 10.4000/sociologico.696

ISSN: 2182-7427

\section{Editora}

CICS.NOVA - Centro Interdisciplinar de Ciências Sociais da Universidade Nova de Lisboa

\section{Refêrencia eletrónica}

Luísa Ferreira da Silva, «O destino como projeto? Racionalidades leigas de promoção da saúde», Forum Sociológico [Online], 22 | 2012, posto online no dia 01 março 2013, consultado o 29 março 2022. URL: http://journals.openedition.org/sociologico/696; DOI: https://doi.org/10.4000/sociologico. 696

Este documento foi criado de forma automática no dia 29 março 2022.

(C) CICS.NOVA 


\title{
O destino como projeto? Racionalidades leigas de promoção da saúde
}

\author{
Luísa Ferreira da Silva
}

\section{A saúde, um fenómeno social}

1 Até finais do século XVIII, a doença era um acontecimento coletivo cuja interpretação era feita à luz da religião e a cura era dirigida à purificação do espírito mais do que à saúde do corpo (Turner, 2000). A partir do século XVIII, em resultado de um processo de causas ambientais múltiplo de melhoria das condições de vida, teve lugar um processo de transição demográfica com consequências no aumento e no envelhecimento da população (McKeown, 1990; McKinlay et al., 1989). A doença passou a ser um acontecimento individual objetivado no corpo.

2 É no contexto da racionalidade de observação do humano que se vem a constituir a medicina do século XIX como especialização do olhar sobre o corpo que se torna o centro das preocupações do conhecimento e sustentáculo do exercício de novas formas de controlo social, o biopoder, assente na vigilância e na autodisciplina que se traduz em disposições concretas que investem o corpo, a saúde, a alimentação, as condições de vida e todo o espaço da existência (Foucault, 1997).

Emerge a figura de "doente" na sua forma moderna de estatuto social atribuído (Herzlich e Pirerret, 1991). Estar doente passa a ser sinónimo de recorrer à medicina como instituição entretanto oficialmente legitimada e detentora do exclusivo da "arte de curar".

4 O estudo de Talcot Parsons (1964), primeira manifestação de interesse da sociologia pelo domínio da doença, encara a saúde como capacidade de desempenhar os papéis sociais que asseguram a integração normativa da sociedade enquanto a doença representa a quebra dessa capacidade e a fuga (não consciente) às pressões do quotidiano. A relação médico-doente, complementar em direitos e responsabilidades, é 
o mecanismo de autorregulação que restaura o funcionamento social reconduzindo os indivíduos doentes aos seus papéis sociais.

5 Em meados do século XX, este modelo do consenso é substituído pelo modelo do conflito. Aqui, a relação terapêutica é o mecanismo de controlo social que implica a definição de doença nas próprias condições institucionais do seu diagnóstico e tratamento, subordinadas à dominância médica (Freidson, 1984). Transformando um problema em doença como entidade própria que só os profissionais podem compreender e desqualificando as sabedorias populares e o autogoverno da vivência da saúde, a afirmação do modelo biomédico comporta um efeito de medicalização da doença que se alarga a áreas cada vez mais extensas da vida social (Illich, 1975).

6 Na década de setenta, o olhar interacionista encara o hospital na perspetiva das relações sociais (Strauss, 1992), contexto estrutural em que profissionais e doentes participam em interações estratégicas com objetivos múltiplos, enfatizando-se o processo negocial de definição das situações em que os participantes se envolvem. A análise da profissão médica (Freidson, 1984) evidencia o hospital como enquadramento institucional da autonomia e da dominância da profissão médica. O estudo de Carapinheiro (1998) sobre serviços hospitalares marcou o início da sociologia da saúde portuguesa, mais tarde seguido por outros, neste tema do hospital e das profissões na área da medicina (Augusto, 2006; Carapinheiro, 2006; Lopes, 2006; Serra, 2006).

7 A mudança cultural que na segunda metade do século XX acentuou o caráter construtivo e reflexivo da identidade foi concomitante com uma nova transição epidemiológica e demográfica que deu relevo aos cuidados com a doença crónica (e a incapacidade). Como estado perspetivado a longo prazo, a doença crónica dilui as fronteiras entre a saúde e a doença que, de realidades em oposição, passam a ser perspetivadas como continuidade atravessada pelo risco e implicando a conexão entre o corpo e o self (Bury, 1982; Charmaz, 1983; Williams, 1984).

8 Neste contexto, o olhar sociológico orientou-se para a subjetividade da doença, a "illness" ou doença do doente e suas implicações na "disease" ou doença no olhar clínico, como entidade própria. Constitui-se progressivamente um saber adquirido relativamente ao "comportamento na doença" - como as pessoas controlam ou monitorizam os seus corpos, definem e interpretam os sintomas, atuam face a eles e usam o sistema de cuidados de saúde (Mechanic, 1960).

9 A doença crónica configurou uma nova definição do papel de doente que assume a negociação como processo de construção de uma nova relação médico-doente (Baszanger, 1986). A relação médico-centrada que a medicina desenvolveu a partir da sua competência para curar a doença aguda tende agora para uma relação entre parceiros de que não é mais possível excluir a subjetividade do sofrimento e as questões identitárias. A assimetria da relação tende a esbater-se e o profissional reconhece-se remetido para uma atitude de negociação da ciência com as condições conjunturais e subjetivas da sua aplicação (Baszanger, 1986; Bury, 1997; Strauss, 1992; Williams, 1999).

\section{Saúde e doença na ordem das relações sociais}

Desde o final do século XVIII, a estatística nascente justificou a prática conjunta política e médica que alia reformas sociais e medidas de higiene e de que nasceu a saúde pública (Herzlich, 2000). Trata-se não só de fazer o poder político intervir com medidas 
reformadoras da organização urbana, mas de intervir no domínio do privado por via da mudança de comportamentos, fazendo a educação da relação com o corpo no sentido das tecnologias sociais do eu como mecanismos de controlo social (Foucault, 1976).

A partir dos finais do século XIX, os progressos da medicina e a capacidade tecnológica de intervenção biomédica deslocam o terreno da intervenção da saúde pública, que passa a dar ênfase à causalidade específica da doença e à intervenção sobre o corpo individual. É no mundo social que a saúde pública vai aumentar a sua influência ideológica generalizando o pensamento higiénico e a noção de risco. Os grupos de população abrangidos e os problemas a que se dirige são cada vez mais numerosos e os agentes diversificam-se (Fassin, 1996).

12 A tensão entre saúde pública e biomedicina é contemporânea do desenvolvimento das políticas de bem-estar que se implantaram nos Estados modernos em resposta à questão social. Ao mesmo tempo que se individualizava, a doença socializava-se, ganhando um novo sentido em relação com o trabalho e a reprodução social na sociedade industrial capitalista (Herzlich e Pierret, 1991).

Retomando o trabalho de Parsons na década de cinquenta, percebe-se melhor a sua leitura da doença como desvio, no contexto de florescimento económico do pós-guerra, com acentuada tendência de prolongamento de vida da população que impregnava a sociedade de otimismo face à medicina. A visão crítica que parte da constatação da permanência das desigualdades como barreiras de classe à mobilidade na sociedade que ideologicamente se afirma vem a surgir após a crise da década de setenta.

14 Com efeito, o papel da medicina é pouco influente na distribuição das desigualdades em saúde, melhorando os indicadores globais mas não diminuindo as diferenças entre os grupos sociais (McKeown, 1990; Chauvin, 1998). Hannay (1980) verificou um importante desnível entre a incidência de doença medicamente diagnosticável e as taxas de recurso à medicina, o clinical iceberg. E o Black Report (Townsend e Davidson, 1983) deu visibilidade de forma sistematizada a que os indicadores de saúde refletem as desigualdades socioeconómicas, o que foi seguidamente sustentado por um grande número de pesquisas que pormenorizam os fatores implicados, como sejam a idade, o género, a etnia, a geografia, a profissão, a situação ocupacional, entre outros (Drulhe, 1996; Silva e Alves, 2003). Pela sua distribuição, a saúde/doença revela-se assim uma construção social na qual a sociedade inscreve uma visão do mundo e a sua organização (Bartley et al., 1998; Leclerc et al, 2000).

O enraizamento social da saúde/doença, condicionada pelo habitus na articulação que faz entre estrutura e agência, confirma-se desde logo na distância que separa o malestar/illness (sentir-se doente) do adoecer (declarar-se doente) e do assumir-se como doente (consultar a medicina ou tornar-se paciente) (Zempléni, 1985). O recurso aos cuidados médicos preventivos e curativos é efetivamente diferenciado consoante os grupos sociais (Blackburn, 1999; Calnan e Williams, 1991), pois é diversa a relação que cada um mantém com o mal-estar e a doença. A perceção da doença, a experiência que dela se faz, ou os diversos comportamentos que ela motiva são condicionados pela subjetividade cultural e individual implicada na variabilidade das imagem do corpo, da resistência à dor, da resposta ao stress e das representações de saúde e de doença (Boltanski, 1971; Herzlich, 1969; Mechanic, 1960; Zola, 1966; Zola, 1973). 


\section{As estratégias políticas da intervenção em saúde}

Se a responsabilidade de procurar e acatar orientação médica em caso de doença se tornou uma imposição interiorizada na generalidade da população a partir de finais do século XIX, a segunda metade do século XX alargou essa preocupação à prevenção do adoecer e, a partir dos finais do século, à de promoção da saúde. O "estilo de vida saudável" impôs-se como uma preocupação "higienista universal" que se estende ao conjunto da população e não já a grupos específicos, alargando a noção tradicional de comportamentos nocivos à saúde para o que é hoje uma noção vasta que abarca todos os comportamentos humanos e multiplica as profissões peritas em especialidades novas (Fassin, 1996). A promoção da saúde - ou “o saudável" - constrói uma nova configuração biopolítica que implica na saúde todos os aspetos da vida em sociedade e faz dela uma responsabilidade de todas as instituições sociais, económicas e políticas, bem como de todos os indivíduos.

Tendo como pilar fundador a conceção biomédica da saúde, a saúde pública reverte os conhecimentos para normas relativas às escolhas individuais implicadas no quotidiano característico da modernidade avançada cujas atitudes e práticas se revelam potencialmente ameaçadoras da saúde. Espera-se dos indivíduos que submetam à normatividade médica sobre saúde não já apenas o seu papel de doentes, mas todos os papéis sociais que desempenham na vida. Alimentação, exercício físico, hábitos tabágicos, etc., são encarados como riscos que no quotidiano exigem escolhas individuais orientadas em função da saúde. A saúde deixou de ser um atributo que se tem, para ser um atributo que se alcança no que representa um processo de "culpabilização da vítima" que ignora a causa-

lidade social e ambiental da doença assim como o contexto social em que tem lugar a decisão individual, designadamente a "sociedade de afluência" (Crawford, 1977; Eyles, 2001; Minkler, 1999).

18 A conceção atual de saúde comunitária, estratégia da OMS para a promoção da saúde, centrada nos atores sociais, coloca ênfase na equidade como objetivo e na participação como método. Promover a saúde significa melhorar a capacidade de resposta aos desafios do ambiente físico e social, ao nível dos indivíduos como ao nível comunitário. o empoderamento das populações é entendido como reforço do exercício da autonomia pelo autocontrolo da própria saúde e do exercício da cidadania pela intervenção coletiva na definição de prioridades da micropolítica (World Health Organization, 1986).

19 Face a esse discurso que afirma a legitimidade da saúde pública na intervenção coordenada global, a análise das estratégias e das práticas no campo da saúde faz sobressair, pelo contrário, um jogo de forças onde se mantém a dominância da biomedicina na definição dos objetivos, da organização e do funcionamento do sistema de cuidados de saúde ainda que crescentemente confrontada pelo poder do eixo administrativo e desafiada pela contestação leiga da autoridade da ciência (Carapinheiro e Page, 2001).

20 Na tensão entre espaços de poder dentro do campo da medicina, a frágil legitimidade da saúde comunitária reflete-se no favorecimento da dinâmica curativa clínica que impõe a secundarização da promoção da saúde como vertente menor da medicina. Reside nessa contradição a perspetiva redutora sobre a promoção da saúde que investe a educação para mudanças comportamentais específicas (Eyles, 2001) num procedimento 
de individualização da doença que resulta em ocultação das condições estruturais nela implicadas devido às desiguais oportunidades na vida social (Blaxter, 1998; Calnan, 1987; Ziglio et al., 2000).

21 Como método, a promoção distancia-se da educação (informativa e pedagógica) pela ênfase que coloca no empoderamento dos agentes individuais e coletivos com vista ao aumento da sua capacidade de escolher e de decidir. No entanto, é na estratégia educativa concebida em termos de campanhas desenhadas com a finalidade de providenciar informação que a promoção da saúde assenta a racionalidade das escolhas informadas (Gastaldo, 1998; Hancock, 1993; White, 2000).

22 A educação supõe que a informação determine a escolha numa atitude racional de tipo científico, linear e objetiva. Ora é no domínio das racionalidades "outras", as do pensamento leigo, que se situa a incompreensão estrutural entre, por um lado, a saúde comunitária perspetivada como ensino do conhecimento médico de prevenção da doença e, por outro, a realidade do mundo da vida com os saberes e práticas que o povoam, feitos de subjetividade da experiência pessoal e relacional e do ambiente cultural em que essa experiência tem lugar.

Alarga-se assim o debate para a discussão antropológica sobre as "crenças" como forma de conhecimento distinta da ciência mas não por isso irracional (Augé e Herzlich, 1984). $\mathrm{Na}$ vida quotidiana, são essas lógicas impregnadas de subjetividade que baseiam os comportamentos de doença e de saúde orientando as interpretações de "comportamento saudável" que condicionam as atitudes que a medicina de saúde comunitária pretende colonizar pelo sistema racional, rejeitando-as como sistema válido de conhecimento (Williams e Popay, 2001).

24 A racionalidade leiga, distante da linearidade e da pretensa neutralidade da racionalidade científica, opera por lógicas complexas que envolvem a subjetividade da experiência humana com os seus valores, símbolos e crenças que são formas de conhecimento cultural (Augé e Herzlich, 1984; Hellman, 2000; Kleinman, 1988; Massé, 1995). No pensamento comum são frequentes as certezas feitas de impressões e de observações contraditórias, numa sujeição às emoções das experiências vividas, às crenças e aos valores, maior do que ao rigor da prova e da argumentação dedutiva. Essa racionalidade leiga ou saber popular que não é irracional como a ciência tende a tratála, mas é uma racionalidade de tipo diferente, social e subjetiva, impregna a generalidade das atitudes e das práticas do dia a dia. Em Portugal, alguns estudos têm averiguado a relação leiga com a saúde (Silva, 2005; Silva, 2008; Bäckström, 2009), com a doença mental (Alves, 2011) e com os medicamentos (Lopes, 2010).

\section{As racionalidades subjetivo-culturais do saber prático de saúde}

Na nossa pesquisa ${ }^{1}$ sobre as lógicas do saudável numa população diversificada do norte de Portugal ${ }^{2}$ (Silva, 2008) investigámos os mecanismos da relação do pensamento leigo ou saber popular com a noção de "saudável", essa nova configuração da saúde que tem como alvo criar identidades saudáveis que produzam saúde para si próprias através da educação e do esforço. 0 objetivo da pesquisa foi a compreensão da interiorização do "saudável" como norma de conduta dirigida ao bem-estar presente e futuro, partindo das questões: na era da construção reflexiva da identidade (Giddens, 1997), qual a presença do conhecimento nas escolhas em matéria de comportamentos de saúde? Como se negoceia o processo de racionalização, que exige escolhas informadas e 
racionais, com o de legitimação tradicional, que implica a marca dos valores e das representações culturais? Como jogam entre si o racional e o subjetivo e com que outras dimensões da realidade social se articulam?

A observação não se dirigiu às práticas em si mesmas, mas às lógicas que lhes subjazem, procurando as racionalidades presentes nas decisões que envolvem escolhas. A questão a perceber não era o que se faz, mas qual o sentido que se dá ao que se faz, quais os valores e crenças, quais as informações e as representações que interagem na construção mais ou menos consciente que determina a ação.

Operando no paradigma qualitativo e numa abordagem compreensiva, a pesquisa teve por fundamento discursos produzidos em entrevistas semiestruturadas dirigidas à observação de como a preocupação com o saudável permeia (o pensamento sobre) as práticas do quotidiano.

28 Foi assim possível identificar significados diversos de saudável, associados a diferentes estilos de relação com a vida e com o corpo que podem ser condensados em atitudes face à saúde que vão da conceção mais tradicional de "saúde-destino" à conceção mais moderna de "saúde-construção". Ambas, no entanto, coincidem num tipo de racionalidade subjetiva que adapta as normas da ciência de forma a fazê-las adequarem-se aos hábitos do quotidiano e aos valores culturais, nomeadamente do ponto de vista da convivialidade e do gosto. No que respeita às opções em matéria alimentar, por exemplo, o gosto (profundamente marcado pela estrutura das relações sociais como demonstrou Bourdieu, 1979) e o convívio comensal são justificação frequente para os comportamentos considerados menos saudáveis. Verifica-se uma forte pressão do grupo no sentido da adoção de comportamentos comuns e a rejeição das opções mais reflexivas no sentido do saudável.

29 Também a governamentalidade como disciplina e autocontrolo aparece sob a forma de interiorizações plurais. Por exemplo, na representação de "saúde-bem-estar" que faz equivaler saudável a "vida natural", percebe-se o distanciamento subjetivo (resistência) relativamente às normas reguladoras da saúde, consideradas não necessárias. Já na representação de "saudável-comportamentos", imbuída da crença na informação médica, é afirmada a autocompetência para decidir as escolhas adequadas ao autocontrolo sobre a própria vida e que só parcelarmente coincidem com as normas científicas. Aqui, a saúde, pela integração da autodisciplina, integra a objetivação racionalizada em lógicas de gestão do quotidiano "construtoras" de um projeto de futuro que integra o bio no psicossocial. Mas, num "estilo" como no outro, com menor ou menor distância (discursiva) entre as afirmações e as práticas, as racionalidades presentes revelam a impregnação pelo subjetivo traduzido em adaptação, mais do que em aplicação linear, das normas (do conhecimento) relativas ao saudável da ciência.

Ou seja, no pensamento leigo, as representações sociais de saudável conciliam a lógica racional-científica da biomedicina com a racionalidade mais subjetiva. Com efeito, os discursos afirmam o conhecimento da relação entre "comportamentos saudáveis" e bem-estar mas dão a ver uma realidade em que o bem-estar é atribuído à vida relacional e ao trabalho (e não aos "comportamentos saudáveis"). Os benefícios que se poderão retirar de um comportamento saudável não são avaliados por si sós como áreas independentes da existência, mas fazem parte de um conjunto complexo em que o bemestar, nas suas vertentes de funcionamento profissional, familiar e de convívio social, proporciona outro tipo de vantagens imediatamente reconhecíveis e que compensam a não concretização dos benefícios hipotéticos da prevenção, justificando que esta seja 
adiada para mais tarde, para "quando sentir necessidade", isto é, quando as limitações físicas associadas à representação de envelhecimento justificarem os comportamentos saudáveis que então resultarão em benefícios evidentes.

31 A ambiguidade é visível também na relação leiga com a noção de risco cuja informação é conhecida no que respeita à generalidade das práticas quotidianas (alimentos contaminados, "lixo alimentar", etc.). Mas a presença desse conhecimento não é convocada pelo pensamento prático. Neste domínio da vida em que rotina e hábito quotidianos são confrontados por argumentos que os põem em questão, o processo de escolha do posicionamento individual revela as negociações íntimas e as racionalidades que as sustêm, atitudes que Giddens (1992) e posteriormente Burton-Jeangros (2004) tipificaram e que também se verificam na nossa amostra (nomeadamente, "pessimismo cínico", "aceitação pragmática" e "optimismo persistente"). Na nossa amostra, a "aceitação pragmática" foi a atitude prevalente. $O$ indivíduo rende-se à necessidade de fazer uma opção que não se situa em espaço de total liberdade, pois tem de entrar em linha de conta com os condicionalismos do contexto social, nos quais se incluem a acessibilidade, o preço e as tradições culinárias, entre outros fatores.

Um resultado particularmente interessante respeita à não interiorização prática, no sentido de disposição para agir (Lahire, 2005), da característica moderna que constitui a identidade e o corpo em projetos de autoconstrução. Com efeito, a noção de "prevenção ativa" da doença e da incapacidade por via da agência individual, que a medicina advoga, está praticamente ausente dos discursos sobre "envelhecer bem", remetida em alguns casos para a "prevenção passiva" (médica) em que à medicina se atribui a capacidade de controlar a doença. No entanto, a atitude perante "a velhice" é caracteristicamente moderna no sentido de "dever moral" de resistir a "ficar velho" (Williams R. cit. por Bunton, 1997). "Temos de vencer o envelhecimento" apela à decisão do indivíduo como construtor de si próprio, numa atitude de supremacia do mental sobre o biológico que significa que, ao mesmo tempo que o corpo envelhece, no sentido de se "degradar", a pessoa pode continuar "jovem".

33 A saúde que aparece no discurso leigo não se refere ao saudável como ideologia de promoção da saúde positiva, nem no que respeita à gestão do quotidiano - no que o saber leigo se advoga competente -, nem no relativo à relação com a instituição médica que é exclusivamente equacionada como competente na doença. A representação de saúde encontrada é de tipo negativo, ausência de doença, com as crenças de base subjetiva (cultural e feita de experiência) a ela associadas. Assim se compreendem os raciocínios que justificam com "ter saúde" ("sou saudável", "sou uma pessoa com saúde", "não tenho problemas") o desinteresse pelo convívio com a medicina preventiva, deixando subentendida a interpretação de que a medicina é para os casos de "não saúde".

Em "discurso público", afirma-se o princípio da adesão à norma da medicalização preventiva mas, nas práticas, essa adesão não se traduz numa atitude generalizada. Como todas as outras práticas em que o indivíduo se investe, o recurso à medicina preventiva resulta de uma negociação íntima em que cada prática não é encarada por si só, mas em relação com as outras práticas que concretizam o sentido da existência. A relação com a doença reconhece o saber da medicina e a ele aceita submetê-la. Mas a doença dos leigos não é a mesma doença dos profissionais, no sentido em que não se refere aos sinais objetivos, inscritos no corpo, que as técnicas de diagnóstico podem 
detetar, mas se refere aos sintomas autopercebidos e à interpretação leiga que deles se faz. É quando se sente doente que o leigo recorre à medicina.

O saber leigo estabelece uma separação entre o que é a "doença", acontecimento episódico e ameaçador, e o que são os "males" do quotidiano, situações de incómodo nas quais inclui as consequências das doenças crónicas depois de diagnosticadas e orientadas terapeuticamente (porque, antes de o serem, são "doença"). E é também a partir da perceção que faz da doença e seus contextos que o pensamento leigo equaciona a causalidade do adoecer, distinguindo as causas exteriores (as circunstâncias da vida) da responsabilidade individual de a elas se expor. Nesses eixos de classificação assenta a concetualização de saúde como não-doença que, situando do lado da saúde os "males normais", constitui o terreno onde se enraíza a representação de saudável dissociada da prevenção da doença.

A "doença" é domínio do saber médico e a ele os doentes têm a responsabilidade de se dirigir em caso de sinais ou sintomas de doença. Os "males normais" podem ou não ser apresentados ao médico consoante os sinais que dão e as circunstâncias em que se revelam, competindo ao indivíduo a responsabilidade de os saber gerir evitando recorrer à medicina sem necessidade. Ter saúde é uma virtude moral e adoecer é cair em desgraça (Cornwell, 1984) e é precisamente isso que se procura impedir pelo evitamento da medicina.

A relação dos leigos com a instituição médica releva assim da autoridade do saber científico especializado no que respeita à "doença", atualizando a leitura de Parsons e não da ciência moderna no que respeita à prevenção como domínio atribuído da instituição médica. No entanto, ela apresenta-se caracteristicamente moderna no que tem de medicalizada no sentido amplo de perceção e utilização da multiplicidade de opções que não se confinam à pessoa de "o médico" como representante da instituição, mas se orientam por entre "os médicos" e "os medicamentos" (e por entre outros sistemas terapêuticos), numa escolha de decisão individual que releva das competências de gestão da doença (Bury, 1997).

Face à "colonização", pela medicina, do pensamento e da atuação sobre a doença que dela torna dependente o saber leigo, este reage pela via da resistência à alienação do poder sobre o corpo-identidade, reivindicando competências de ação no âmbito da saúde. Mas simultaneamente com essa cultura de resistência à medicalização do quotidiano, o domínio da doença apresenta-se imbuído da colonização pela racionalidade científico-médica, delimitada a resistência à contestação indireta da exclusividade da autoridade da medicina. Diversificam-se os recursos a vários profissionais médicos e não médicos e recorre-se por autodecisão aos meios medicamentosos numa lógica de subversão que retira à medicina a prerrogativa da decisão sobre o seu uso, ao mesmo tempo que demonstra também a impregnação pela ideologia do consumo.

\section{Conclusão}

39 A análise dos discursos no domínio das práticas e representações da saúde dá a ver "o saudável" como subjetivo e cultural, muito mais do que racional-científico, embora contenha a informação da ciência e com ela interaja. A reflexividade como processo de implicação do "eu" com o conhecimento (Giddens, 1992) apresenta-se, nas racionalidades leigas, carregada de ambiguidades concetuais e de relativizações das 
normas que lhe estão associadas, numa coerência interna que se refere à articulação do conhecimento com a teia dos valores, símbolos, significados e normas, com hábitos adquiridos e com constrangimentos sociais (Nicolini e Holti, 2003). As escolhas de "estilo de vida", espaços de objetivação do saudável, não são livres em absoluto, mas condicionadas pela estrutura social e incorporadas em sistemas simbólicos contingentes porque expressivos e estéticos. Ou seja, com Lash (2000) podemos concluir que a identidade não é apenas individual mas também social, querendo-se reconhecida e confirmada pelos outros.

O trabalho e a família, como condições estruturais da integração, e "o gosto" como disposição estruturante, tal como demonstrou Bourdieu (1979), orientam e condicionam a construção da identidade de forma mais marcante do que a preocupação moderna com o saudável. "Agir saudável” é uma imposição disciplinar (Foucault, 1976) que requer esforço de autocontrolo nas sociedades modernas em que o consumo se tornou cultura (Baudrillard, 1981) e a saúde deixou de ser uma dádiva para ser uma tarefa produtiva de autorrealização (Cockerham et al., 1997). No campo do saudável, dinâmica pela qual a ciência entra no "mundo da vida" (Schutz, s.d.) através do sistema especializado da medicina, a identidade incorporada em práticas assume-se como projeto aos níveis psico e social mas não no nível bio a que a ideologia do saudável dá prioridade. A lógica da ciência que pretende orientar as escolhas dos indivíduos em matéria de saúde corporal constitui informação que o pensamento leigo integra como crença, mas não conhecimento assimilado no sentido de impregnação da ação (Lahire, 2005). Como se a subjetividade imbuída nas atividades do quotidiano resistisse a alienar o "saber prático" em matéria de saúde, recusando a objetivação que especializa o elemento biológico.

Os processos de lidar com a informação revelam-se deliberadamente defensivos em relação à perceção de vulnerabilidade subjacente à sociedade do risco (Beck, 1998), fortemente resistentes à invasão do quotidiano e das representações a ele associadas de bem-estar e de saúde, por uma racionalização disciplinar dirigida à vigilância do corpo.

A subjetividade na relação do eu com "as saúdes" afirma-se em processos diferentes, circunstanciais (cuja relação com as posições e os capitais sociais poderão constituir o objeto de outros estudos), que apontam para identidades mais e menos "modernas", no sentido de impregnadas de objetivação e racionalização. A consciência do corpo e o interesse que se lhe atribui não se manifesta como preocupação construtiva no sentido de autorrealização da saúde por via de comportamentos "higiénicos" (Herzlich, 1969), configurando uma "cultura de resistência" que contesta a objetivação das práticas quotidianas como actividades de orientação especializada (Fox, 1998).

0 projeto moderno das identidades que se autoconstroem aparece nesta pesquisa referido ao bem-estar familiar e profissional, mas não à saúde que se dá a ver como questão de destino (mais ou menos religioso ou secular).

44 A saúde como "destino", mais do que como resultado da autoprodução do estilo de vida, foi o que esta pesquisa encontrou como tendência claramente dominante. 


\section{BIBLIOGRAFIA}

ALVES, F. (2011), A Doença mental nem sempre é doença. Racionalidades leigas de saúde e doença mental, Porto, Afrontamento.

AUGÉ, M. e C. Herzlich (1984), Le sens du mal, Paris, Éditions des Archives Contemporaines.

AUGUSTO, A. (2006), "Infertilidade e reprodução medicamente assistida: definição de contextos e produção de significados”, in G. Carapinheiro (org.), Sociologia da Saúde; Estudos e Perspectivas, Coimbra, Pé de Página Editores.

BÄCKSTRÖM, B. (2009), Saúde e imigrantes: as representações e as práticas sobre a saúde e a doença na comunidade cabo-verdiana em Lisboa, Lisboa, ACIDI.

BARTLEY, M.; D. Blane e G. Smith (1998), “Beyond the Black Report”, Sociology of Health \& Illness, 20 (5): 563-577.

BASZANGER, I. (1986), "Les Maladies chroniques et leur ordre négocié”, Revue Française de Sociologie, XXVII: 3-26.

BAUDRILLARD, J. (1981), A sociedade de consumo, Lisboa, Edições 70.

BECK, U. (1998), La Sociedad del riesgo, Barcelona, Paidós.

BLACKBURN, C. (1999), "Poor health, poor health care - the experiences of low-income households with children”, in M. Purdy e D. Banks (eds.), Health and exclusion: policy and practice in health provision, Londres, Routledge.

BLAXTER, M. (1998), Health and lifestyles, Londres, Routledge.

BOLTANSKI, L. (1971), “Les Usages sociaux du corps”, Annales Économies, Sociétés, Civilisations, 26: 205-233.

BOURDIEU, P. (1979), La Distinction - critique sociale du jugement, Paris, Les Éditions de Minuit. BUNTON, R. (1997), "Popular health, advanced liberalism and good housekeeping magazine", in A. Petersen e R. Bunton (eds.), Foucault - Health and Medicine, Londres, Routledge.

BURTON-JEANGROS, C. (2004), Cultures familiales du risque, Paris, Anthropos.

BURY, M. (1982), “Chronic illness as biographical disruption”, Sociology of Health and Illness, 4 (2): $167-182$

BURY, M. (1997), Health and illness in a changing society, Londres, Routledge.

CALNAN, M. (1987), Health and illness the lay perspective, Londres e Nova Iorque, Tavistock Public.

CALNAN, M. e Williams, S. (1991), "Style of life and the salience of health: an exploratory study of health related practices in households from differing socio-economic circumstances", Sociology of Health and Illness, 13 (4): 506-529.

CARAPINHEIRO, G. (1998), Saberes e poderes no hospital, Porto, Afrontamento.

CARAPINHEIRO, G. e P. Page (2001), “As determinantes globais do sistema de saúde português” in Risco social e incerteza. Pode o estado social recuar mais?, ed. de P. Hespanha e G. Carapinheiro, Porto, Afrontamento, pp: 81-121. 
CARAPINHEIRO, G. (2006), “A Saúde enquanto matéria política”, in G. Carapinheiro (ed.), Sociologia da Saúde; Estudos e Perspectivas, Coimbra, Pé de Página Editores.

CHARMAZ, K. (1983), "Loss of self: a fundamental form of suffering in the chronically ill", Sociology of Health and Ilness, 5 (2): 168-195.

CHAUVIN, P. (1998), "Précarisation sociale et état de santé: le renouvellement d'un paradigme épidiémiologique”, in J. Lebas e P. Chauvin (eds.), Précarité et santé, Paris, Flammarion.

COCKERHAM, W. et al. (1997), "Conceptualizing contemporary health lifestyles: Moving Beyond Weber”, The Sociological Quarterly 38(2): 321-342.

CORNWELL, J. (1984), Hard-earned lives, Londres, Tavistock Publications.

CRAWFORD, R. (1977), "You are dangerous to your health: the ideology and politics of victim blaming", International Journal of Health Services, 7 (4): 663-681.

DRULHE, M. (1996), Santé et société - le façonnememt sociétal de la santé, Paris: PUF.

EYLES, J. (2001), “What determines health? To where should we shift resources? Attitudes towards the determinants of health among multiple stakeholder groups in Prince Edward Island, Canada", Social Science and Medicine, 53 (12): 1611-1619.

FASSIN, D. (1996), L'espace politique de la santé, Paris, PUF.

FOUCAULT, M. (1976), La Volonté de Savoir. Histoire de la Sexualité 1., Paris, Gallimard.

FOUCAULT, M. (1997), Naissance de la Clinique, Paris, PUF.

FOX, N. (1998), "The Promise of postmodernism for the sociology of health and medicine", in G. Scambler e P. Higgs (eds.), Modernity, medicine and health - debate on postmodernism, Londres e Nova Iorque, Routledge.

FREIDSON, E. (1984), La Profession médicale, Paris, Payot.

GASTALDO, D. (1998), "Is Health education good for you? Re-thinking health education through the concept of bio-power", in A. Petersen e R. Bunton (eds.), Foucalt - Health and Medicine, Londres e Nova Iorque, Routledge.

GIDDENS, A. (1992), As Consequências da modernidade, Oeiras, Celta.

GIDDENS, A. (1997), Modernidade e identidade pessoal, Oeiras, Celta.

HANCOCK, T. (1993), “The Health City from concept to application - implications for research", in J. Davies e M. Kelly (eds.), Health Cities - research and practice, Londres, Routledge.

HANNAY, D. (1980), “The «Iceberg» of Illness and «Trivial» Consultations”, J. of the Royal College of General Practitioners, 551-554.

HELLMAN, C. (2000), Culture, health and illness, Oxford, Butterworth-Heinemann.

HERZLICH, C. (1969), Santé et maladie - analyse d'une représentation sociale, Paris, École des Hautes Études en Sciences Sociales.

HERZLICH, C. e Pierret, J. (1991), Malades d'hier, malades d'aujourd'hui, Paris, Payot.

HERZLICH, C. (2000), "Médecine moderne et quête de sens: la maladie signifiant social” in M. Augé e C. Herzlich, Le Sens du mal, Paris: Éditions des Archives Contemporaines, pp. 189-216.

ILLICH, I. (1975), Némésis Médicale - L'expropriation de la Santé, Paris, Seuil.

KLEINMAN, A. (1988), The Illness Narratives, Nova Iorque, Basic Books, Inc. 
LAHIRE, B. (2005), “Patrimónios Individuais de Disposições - Para uma sociologia à escala individual”, Sociologia, Problemas e Práticas(49): 11-42.

LASH, S. (2000), “A Reflexividade e os seus duplos. Estrutura, estética, comunidade” in U. Beck, A. Giddens e S. Lash, Modernização reflexiva. Política, tradição, e estética no mundo moderno, Oeiras, Celta, pp. 105-164 e 187-204.

LECLERC, A. et al. (2000), Les inégalités sociales de santé, Paris, La Découverte.

LOPES, N. M. (2006), “Tecnologias da saúde e novas dinâmicas de profissionalização”, in G. Carapinheiro (org.), Sociologia da Saúde; Estudos e Perspectivas, Coimbra, Pé de Página Editores. LOPES, N. M. (2010), Medicamentos e Pluralismo terapêutico, práticas e lógicas sociais em mudança, Porto, Afrontamento.

MASSÉ, R. (1995), Culture et santé publique, Montréal e Paris, Gaetan Morin.

McKEOWN, T. (1990), “The medical contribution”, in N. Black et al. (eds.), Health and Disease - a Reader, GB e EUA, Open University Press.

McKINLAY, J. et al. (1989), "A review of the evidence concerning the impact of medical measures on recent mortality and morbidity in the United States", International Journal of Health Services, 19 (2): 181-208.

MECHANIC, D. (1960), “The concept of illness behavior”, J. Chrom. Dis., 15 (2): 189-194.

MINKLER, M. (1999), "Personal responsibility for health? A review of the arguments and the evidence at Century's end", Health Education and Behavior, 26 (1): 121-140.

NICOLINI, D. e R. Holti (2003), “Teorização baseada na prática e compreensão da mudança participativa nas organizações", Cadernos de Ciências Sociais 23(Dezembro): 21-39.

PARSONS, T. (1964), The Social System, Nova Iorque, Free Press.

SCHUTZ, A. (s.d.), The Phenomenology of the social world, Evanston, Northwestern University Press.

SERRA, H. (2006), "Da tecnologia à tecnocracia. Estratégias de poder médico no limiar das fronteiras entre especialidades: o caso da transplantação hepática”, in G. Carapinheiro (org.), Sociologia da Saúde; Estudos e Perspectivas, Coimbra, Pé de Página Editores.

SILVA, L. (2005), Saúde/Doença é questão de cultura - Atitudes e comportamentos de saúde materna nas mulheres ciganas em Portugal, Lisboa, Alto Comissariado para a Imigração e Minorias Étnicas.

SILVA, L. F. (2008), Saber Prático de Saúde, As lógicas do saudável no quotidiano, Porto, Afrontamento.

SILVA, L. F. e F. Alves (2003), A Saúde das Mulheres em Portugal, Porto, Afrontamento.

STRAUSS, A. (1992), La trame de la négociation, Paris, L'Harmattan.

TOWNSEND, P. e N. Davidson (eds.) (1983), Inequalities in health - the black report, GB, Penguin Books.

TURNER, B. (2000), "The History of the Changing Concepts of health and Illness: Outline of a General Model of Illness Categories", in G. Albrecht, R. Fitzpatrick e S. Scrimshaw (eds.), The SAGE Handbook of Social Studies in Health and Medicine, Londres, Sage Publications. 
WHITE, D. (2000), “Consumer and community participation: a reassessment of process, impact and value", in G. Albrecht et al. (eds.), The SAGE Handbook of Social Studies in Health and Medicine, Londres, Sage.

WILLIAMS, G. (1984), "The genesis of Chronic Illness: narrative re-construction", Sociology of Health \& Illness, 6: 175-200.

WILLIAMS, G. e J. Popay (2001),"Lay health knowledge and the concept of the lifeworld"', in G. Scambler, (ed.), Habermas, critical theory and health, Londres e Nova Iorque, Routledge.

WILLIAMS, S. (1999), "Is anybody there? Critical realism, chronic illness and the disability debate", Sociology of Health \& Illness, 21 (6): 797-819.

WORLD HEALTH ORGANIZATION (1986), “Ottawa Charter for Health Promotion”, First International Conference on Health Promotion, Ottawa, Canadá.

ZEMPLÉNI, A. (1985), “La Maladie et ses Causes”, L'Ethnographie, 2: 13-44.

ZIGLIO, E. et al. (2000), "Health promotion development in Europe: achievements and challenges”, Health Promotion International, 15 (2): 143-154.

ZOLA, I. (1966), "Culture and symptoms - an analysis of patients' presenting complaints", American Sociological Review, 31 (5): 615-630.

ZOLA, I. (1973), "Pathways to the doctor - from person to patient", Social Science \& Medicine, 7: 677-689.

\section{NOTAS}

1. Pesquisa realizada no âmbito do CEMRI-UAb com apoio da FCT-Feder.

2. Amostra: 50 mulheres e 31 homens, dos 24 aos 72 anos, residentes no Norte de Portugal, diversificados quanto a género, idade, tipo de família, local de vida, escolaridade, profissão e posição de classe. A amostra não tem representatividade estatística. Foi construída aleatoriamente a partir de amostra de crianças de escolas públicas e privadas do ensino básico e secundário em quatro regiões distintas: Porto, Bragança, Viana e Vale de Cambra.

\section{RESUMOS}

A responsabilidade de procurar orientação médica em caso de doença tornou-se uma imposição interiorizada na generalidade da população a partir de finais do século XIX. A segunda metade do século XX alargou essa preocupação à prevenção do adoecer e, nas últimas décadas do século, à de promoção da saúde, numa estratégia que se caracteriza pela ênfase na capacidade do indivíduo para gerir os riscos. Essa é a normatividade que dá conteúdo ao "saudável" como "estilo de vida" a nível dos comportamentos individuais. A nossa pesquisa sobre o pensamento leigo de saúde mostra que as racionalidades leigas são mais complexas do que supõem os modelos de educação para a saúde e que a subjetividade cultural influencia as avaliações que justificam as escolhas relativas à saúde. Encarar a saúde como projeto que se constrói não é a atitude dominante no pensamento leigo onde saúde (ainda) rima com destino. O texto começa por 
apresentar a história da construção social de saúde e segue pela apresentação e discussão dos resultados de pesquisa empírica sobre "o saudável".

The responsibility to seek medical advice in case of disease has become internalized from the late nineteenth century onwards. The second half of the twentieth century extended this concern to the prevention of illness and to the promotion of health. The latter is a strategy of attributing to individuals the responsibility to manage risks. This normativity gives content to the concept of "healthy" as "lifestyle" at the level of individual behavior. Our research on lay health shows that lay rationalities are complex and evaluations choices related to health are influenced by cultural subjectivity. Health as a project is not the prevailing attitude in lay knowledge. Lay health (still) rhymes with destiny. This paper begins by presenting the history of the social construction of health and is followed by the presentation and discussion of results of empirical research on the concept of "healthy".

ÍNDICE

Keywords: health, healthy, lay knowledge of health, rationalities

Palavras-chave: saúde, saudável, pensamento leigo de saúde, racionalidades

\section{AUTOR}

LUÍSA FERREIRA DA SILVA

Investigadora do CAPP-ISCSP-UTL (luisafs@iscsp.utl.pt) 